\title{
An Injector for a Multi Ion Beam Driver Linac*
}

\author{
H. Podlech, D. Gorelov, J.-W. Kim, F. Marti, R. York \\ National Superconducting Cyclotron Laboratory, East Lansing, MI-48824, USA
}

\section{Abstract}

An advanced facility for the production of exotic shortlived isotopes far from stability (RIA) could use as the driver a high power $\mathrm{cw}$ superconducting linac [1]. Due to the wide range of particle velocities $(\beta=0.019-0.81)$, different cavity types are required. This paper describes a possible design for the injector portion (up to $\beta=0.1$ ) of the driver linac. The proposed injector design consists of a multi-harmonic buncher, an RFQ ( $\mathrm{f}=57.5 \mathrm{MHz})$, 4-gap fork resonators $(\mathrm{f}=57.5 \mathrm{MHz})$, and finally, 2-gap quarter wave resonators $(\mathrm{f}=86.25 \mathrm{Mhz})$. The results of numerical simulations and a comparison different possible RFQ designs (4-vane, IH) are presented.

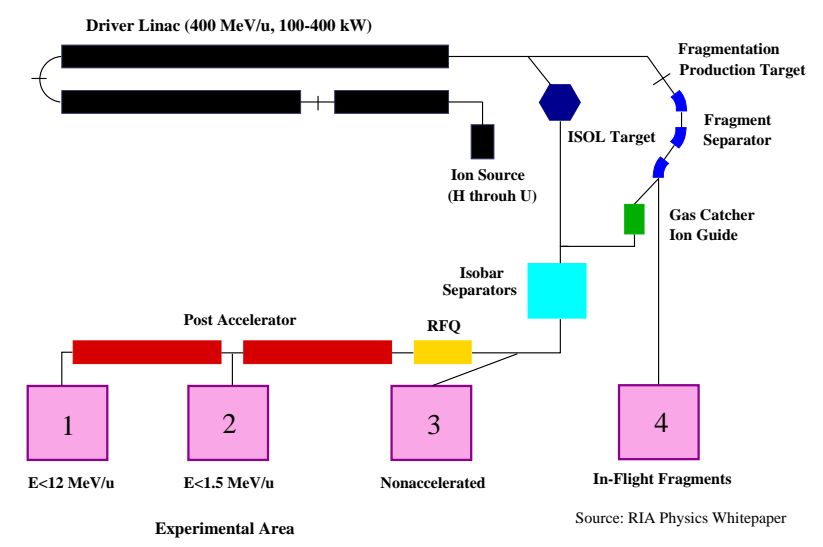

Figure 1: Schematic layout of the Rare Isotope Accelerator (RIA).

\section{INTRODUCTION}

Experiments with radioactive ion beams far from stability is a major frontier in nuclear physics. In the last several years, a concept for a world-class radioactive ion beam facility has been developed [1]. The proposed design for the Rare Isotope Accelerator (RIA) project includes a high power, cw linac. To limit the power consumption, all accelerating structures with $\beta>0.019$ are superconducting. The driver linac will provide beams over the whole mass range from hydrogen through uranium with energies between $400 \mathrm{MeV} / \mathrm{u}(\mathrm{U})$ and $900 \mathrm{MeV}(\mathrm{H})$ and a beam power between $100 \mathrm{~kW}$ and $400 \mathrm{~kW}$.

\section{RFQ}

The first accelerating structure is a normal conducting radio frequency quadrupole (RFQ) accelerator operated at

\footnotetext{
${ }^{*}$ Work supported by NSF Cooperative Agreement \# PHY-952844
}

$\mathrm{f}=57.5 \mathrm{MHz}$. RFQ resonators are well established structures for the acceleration of low energy ion beams with simultanious strong transverse focusing [2]. Two possible solutions for RIA have been considered, a 4-vane RFQ and an IH-type RFQ.

\subsection{4-vane $R F Q$}

The 4-vane RFQ is a cylindrical resonator with four vanes placed symmetrically within the cavity. It is operated in the $\mathrm{TE}_{21(0)}$ mode. The low frequency of $57.5 \mathrm{MHz}$ leads to a rather large diameter of about $100 \mathrm{~cm}$. MAFIA simulations have shown a high efficiency $\left(\mathrm{Z}_{M A F I A}=680 \mathrm{k} \Omega \mathrm{m}\right)$ because the vane charge current is distributed very uniformly along the whole structure resulting in a high shunt impedance.

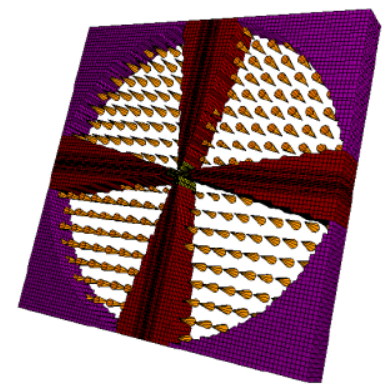

Figure 2: The $57.5 \mathrm{MHz}$ 4-vane RFQ with the characteristic magnetic field of the $\mathrm{TE}_{21(0)}$ mode.

\begin{tabular}{|l|c|c|}
\hline parameter & 4-vane RFQ & IH-RFQ \\
\hline $\mathrm{f}[\mathrm{MHz}]$ & 57.5 & 57.5 \\
Diameter $[\mathrm{cm}]$ & 100 & 45 \\
Length $[\mathrm{cm}]$ & 260 & 260 \\
$\mathrm{Z}[\mathrm{k} \Omega \mathrm{m}]$ & 680 & 390 \\
$\mathrm{Q}_{0}$ & 20000 & 12000 \\
$\mathrm{U}_{\text {vane }}[\mathrm{kV}]$ & 75 & 75 \\
$\mathrm{E}_{\text {in }}[\mathrm{keV} / \mathrm{u}]$ & 13 & 13 \\
$\mathrm{E}_{\text {out }}[\mathrm{keV} / \mathrm{u}]$ & 169 & 169 \\
$\epsilon_{\text {long,out }}[\pi \mathrm{keV} / \mathrm{u} \cdot \mathrm{ns}]$ & 0.14 & 0.14 \\
\hline
\end{tabular}

Table 1: Comparison between the 4-vane and IH-type RFQ. The shunt impedance and Q-value are the result of MAFIA simulations. The longitudinal emittance is for a single charge state $\left(\mathrm{U}^{28+}\right)$. 


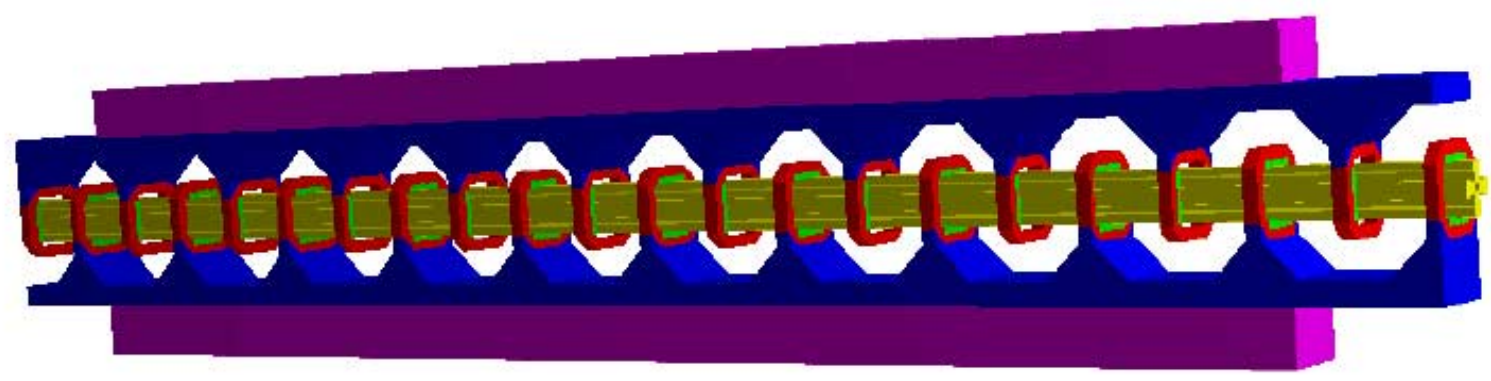

Figure 3: The inner structure of the IH-RFQ consists of two ridges carrying the support rings and the electrodes.

\subsection{IH-type RFQ}

A different possibility for RIA is an IH-type RFQ. It is a cylindrical resonator operated in the $\mathrm{TE}_{11(0)}$ mode. The resonance structure consists of two ridges carrying the support rings and mini-vane like electrodes. The simulations have shown that the shunt impedance is lower compared with a 4-vane RFQ, but due to the higher capacitance, the strucure is much more compact. The result is a diameter half as large as for the 4-vane RFQ. See table 1. In addition, the IH RFQ is easily tunable and not as sensitive to mechanical perturbations [3].

Figure 3 shows the resonance structure of the IH-RFQ. This RFQ is similar to the RFQ of the new high current injector at GSI which has been successfully commissioned in 1999 [4].

The distance and the width of the support rings have been
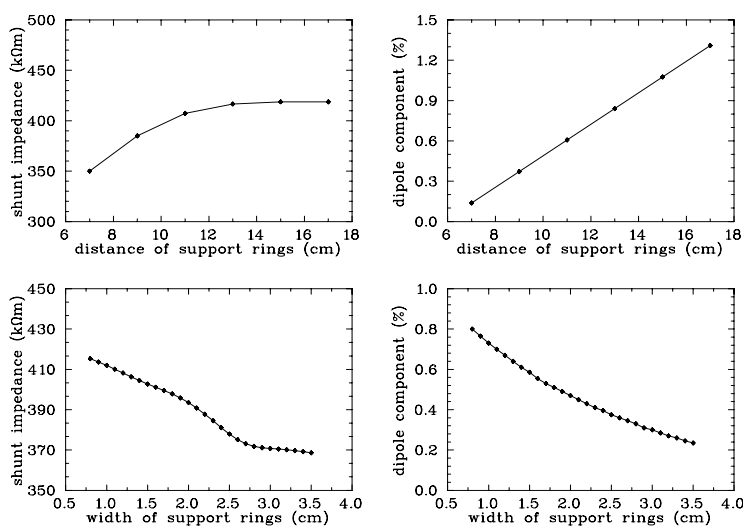

Figure 4: Shunt impedance and dipole component of the IH-RFQ as function of the distance and width of the support rings (MAFIA).

optimized with MAFIA in order to minimize the dipole component and to maximize the shunt impedance. See fig. 4. A width of $2 \mathrm{~cm}$ and a distance of $12 \mathrm{~cm}$ lead to a calculated shunt impedance of $390 \mathrm{k} \Omega \mathrm{m}$ and a dipole component of $0.7 \%$.

Given in Table 2 are the percentage of the power losses for different structure components. Only $7 \%$ of the power is dissipated on the electrodes. Therefore, it is possible to cool the electrodes indirectly.

In addition, simulations with the program package Analyst $^{T M}$ Accelerator Edition [5] have been performed as cross-check with the MAFIA simulations. Both programs delivered the same results within two percent.

\subsection{RFQ beam dynamic}

RFQ beam dynamic calculations have been performed using the PARMTEQ code. For uranium, the RFQ must simultaniously accelerate two charge states to meet the beam power requirements. Therefore, the longitudinal properties of the beam from the RFQ is of special concern. A program has been developed to optimize the properties of the RFQ and the longitudinal emittance. Fig. 5 shows some results of these simulations. The first two plots show the synchronous phase and the modulation, respectively. The plots in the second row show the transverse phase space and the plots in the third row the phase width and energy width of the beam. The transverse normalized emittance growth is $3 \%$ and the longitudinal emittance is $0.14 \pi \mathrm{keV} / \mathrm{u} \cdot \mathrm{ns}$ for a single charge state $\mathrm{U}^{28+}$ and prebunched beam. The electrodes have a length of $260 \mathrm{~cm}$ and voltage of $75 \mathrm{kV}$. Table 1 summarizes the parameter of the RFQ.

\begin{tabular}{|l|c|}
\hline component & power losses \\
\hline tank & $53 \%$ \\
ridges & $31 \%$ \\
support rings & $9 \%$ \\
vanes & $7 \%$ \\
\hline$\Sigma$ & $100 \%$ \\
\hline
\end{tabular}

Table 2: Relative power losses of the IH-RFQ (MAFIA).

\section{SUPERCONDUCTING CAVITIES}

After the RFQ, the driver linac consists of superconducting cavities. Up to approximately the $85 \mathrm{MeV} / \mathrm{u}$ point, drift tube cavities are foreseen whereas elliptical 6-cell cavities are proposed for the remainder of the linac [5]. 

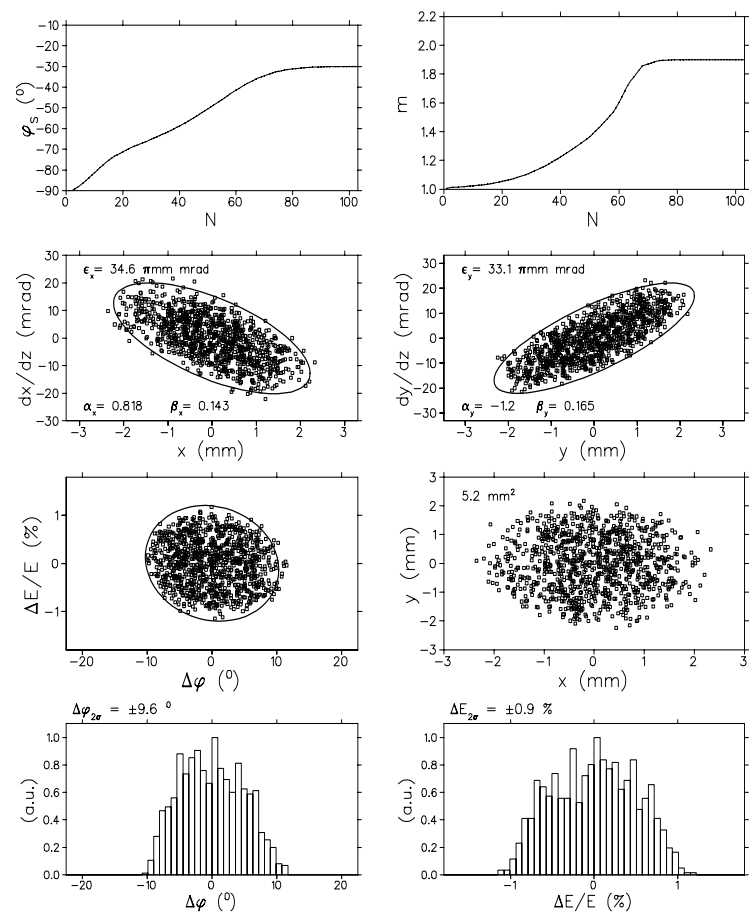

Figure 5: Results of the PARMTEQ simulations. As input a prebunched beam has been used.

The injector part could consist of three types of superconducting coaxial-line cavities. The first two types are 4-gap fork resonators very similar to those presented by ANL [6] (see fig. 6, left). They are operated at $\mathrm{f}=57.5 \mathrm{MHz}$ and designed for a particle beta of 0.02 and 0.03 , respectively.

The third type of the drift tube cavities is a 2-gap quarter wave resonator (QWR) operated at $\mathrm{f}=86.25 \mathrm{MHz}$ and optimized for a beta $=0.06$ (see fig. 6, right). Due to the broad transit time factor of the QWR, it can accelerate ions efficiently up to $\beta=0.1$. The number of required quarter wave resonators is 32 assuming a gradient of $\mathrm{E}_{a c c}=6 \mathrm{MV} / \mathrm{m}$ and $q / A=29 / 238$. All cavities have been simulated with

\begin{tabular}{|c|c|c|c|}
\hline Parameter & Fork1 & Fork2 & QWR \\
\hline $\mathrm{f}[\mathrm{MHz}]$ & 57.5 & 57.5 & 86.25 \\
\hline$\beta$ & 0.02 & 0.03 & 0.06 \\
\hline length $_{\text {total }}[\mathrm{cm}]$ & 109 & 102 & 87 \\
\hline $\mathrm{G}=\mathrm{R}_{s} \mathrm{Q}_{0}[\Omega]$ & 15.3 & 19.4 & 25.2 \\
\hline $\mathrm{R}_{p} / \mathrm{Q}_{0}[\Omega]$ & 1810 & 2274 & 718 \\
\hline $\mathbf{R}_{p} \mathbf{R}_{s}\left[10^{3} \Omega^{2}\right]$ & 27.6 & 44.3 & 18.1 \\
\hline $\mathrm{E}_{a c c}[\mathrm{MV} / \mathrm{m}]$ & 3.27 & 3.46 & 6.0 \\
\hline $\mathrm{E}_{p} / \mathrm{E}_{a c c}$ & 4.9 & 4.7 & 5.0 \\
\hline $\mathrm{B}_{p} / \mathrm{E}_{a c c}[\mathrm{G} /(\mathrm{MV} / \mathrm{m})]$ & 77 & 85 & 117 \\
\hline $\mathrm{W} / \mathrm{E}_{a c c}\left[\mathrm{~mJ} /(\mathrm{MV} / \mathrm{m})^{2}\right]$ & 112 & 154 & 161 \\
\hline $\mathrm{U}_{e f f}[\mathrm{MV}]$ & 0.72 & 1.04 & 1.32 \\
\hline number of cavities & 2 & 5 & 32 \\
\hline
\end{tabular}

Table 3: Parameters of the first three drift tube cavities.

MAFIA. Table 3 shows some paramter and the most im-


Figure 6: Magnetic field of the $\beta=0.03$ fork cavity and of the $\beta=0.06$ quarter wave resonator.

portant electromagnetic properties of the cavites.

\section{CONCLUSION}

A possible solution of an injector for a cw superconducting high power linac has been presented that would consist of a $57.5 \mathrm{MHz}$ normal conducting RFQ and 39 superconducting coaxial-line resonators operated at frequencies of 57.5 and $86.25 \mathrm{MHz}$.

As the first accelerating section, a 4-vane and an IH-type RFQ have been considered. Due to the advantages of the IH-RFQ (more compact, easyly tunable, less sensitive) this structure seems to be more favourable for the low frequency despite the smaller shunt impedance.

\section{REFERENCES}

[1] K.W. Shepard et al., Proceedings of the $9^{\text {th }}$ Workshp on RF Superconductivity, Report LA-13782-C, LANL, Los Alamos, 2000, p. 345-351

[2] I.M. Kapchinsky, V.A. Tepliakov, Prib. Tekh. Eksp. 2, 19-22 (1970)

[3] U. Ratzinger, Habilitationsschrift, Universität Frankfurt, Germany, 1998

[4] U. Ratzinger, Proceedings of the EPAC2000, Vienna, Austria

[5] W. Hartung et al., in this proceedings

[6] K.W. Shepard, Proceedings of the LINAC conference 2000, Monterey, USA

[7] http://www.staarinc.com 